\title{
Study on three phase foam for Enhanced Oil Recovery in extra-low permeability reservoirs
}

\author{
Ming Zhou ${ }^{1,2, *}$, Juncheng $\mathrm{Bu}^{1}$, Jie Wang ${ }^{1}$, Xiao Guo ${ }^{2}$, Jie Huang ${ }^{1}$, and Min Huang ${ }^{1}$ \\ ${ }^{1}$ School of Material Science and Engineering, Southwest Petroleum University, Chengdu, Sichuan 610500, PR China \\ 2 State Key Laboratory of Oil and Gas Reservoir Geology and Exploitation Engineering, Southwest Petroleum University, \\ Chengdu, Sichuan 610500, PR China
}

Received: 24 February 2018 / Accepted: 5 September 2018

\begin{abstract}
Poly (MSt-MMA) nanosphere as foam stabilizing agent was synthesized by emulsion polymerization. The three phase foam was prepared with Disodium 4-Dodecyl-2,4'-Oxydiben Zenesulfonate (DOZS) as foaming agent, Hydrolyzed Polyacrylamide (HPAM) and synthesized poly (MSt-MMA) nanospheres as the mixed foam stabilizing agents. It had outstanding foaming performance and foam stability. The optimal three phase foam system consisting of $0.12 \mathrm{wt} \%$ HPAM, $0.04 \mathrm{wt} \%$ poly (MSt-MMA) nanospheres and $0.12 \mathrm{wt} \%$ DOZS by orthogonal experiment, had high apparent viscosity, which showed that three components had a very good synergistic effect. The three phase foam's temperature tolerance and salt tolerance were researched in laboratory tests. Flooding oil experiment showed that the average displacement efficiency of three phase foam system was $16.1 \mathrm{wt} \%$ in single core experiments and $21.7 \mathrm{wt} \%$ in double core experiments. Resistance coefficient of low permeability core was more than those of high permeability core, but their residual resistance coefficients were small. The results of core experiment and pilot test indicated that the three phase foam had good profile control ability and generated low damage to the low permeability layer for extra-low permeability reservoirs. Three phase foam flooding has great prospects for Enhanced Oil Recovery (EOR) in extra-low permeability reservoirs.
\end{abstract}

\section{Introduction}

At present, high water-cut and high salinities are issues in the many oilfields in China, such as the Zhongyuan Oilfield, the Changqing Oilfield and the Tarim Oilfield [1]. Therefore, Enhanced Oil Recovery (EOR) technology is of significant interest and one of the most important drivers for developing oil and gas fields [2, 3]. Chemical flooding is an important the mature technique of EOR, which includes polymer flooding, surfactant flooding, foam flooding, alkaline flooding and combinational flooding [4-6]. Polymers have been used successfully in EOR for quite a long time. The polymers as flooding agent play an important role in chemical flooding for tertiary oil recovery [7, 8]. Polymer solutions, compared with water, show non-Newtonian rheological behavior, such as shear thinning and viscoelastic behavior. Adding a polymer to water increases the viscosity of the aqueous solution to obtain a better mobility ratio. However, a certain amount of crude oil still remains in the oil reservoir [9].

Foam not only has a certain ability to expand the sweep volume, but also can improve the displacement

\footnotetext{
* Corresponding author: $\mathrm{mr}$.zhouming@163.com
}

efficiency [10]. Foam is becoming increasingly attractive as a mobility profile control agent [11]. Nevertheless, the foam is a kind of unstable thermodynamic system and a spontaneous process reduces the energy of the system. From the above analysis, it can be concluded that the foam is an unstable system, which determines relative stability of the foam itself [12-14].

Cross-linked polymer spheres have the characteristics of relative thermal stability, great water absorbency, controllable size, swelling and deformation, which clearly differs from preformed gel particles [15, 16]. The nanospheres have a good injection and migration and can plug high permeability layer in the low permeability reservoir because they can deform under pressure and across oil bearing reservoirs to control deep profiles [17]. As a result, they can change the direction of the injected water for the ultimate purpose of enhancing oil recovery [18].

The Composite Index (FCI) of conventional foam is very low in the high salinity solution because the foaming volume is small and the half-life is remarkably short [19]. To solve this problem, the $\mathrm{P}$ (MSt-co-MMA) nanospheres were prepared by emulsion polymerization at first, then the three phase foam system consisting of surfactant, $\mathrm{P}$ (MSt-co-MMA) nanospheres and polymer KYPAM-II 
was prepared in this paper. The three phase foam system cannot only improve the stability of the foam, but also improve the foaming property of the foam. It can achieve the higher effectiveness for EOR.

\section{Experiment}

\subsection{Materials}

Methyl Styrene (MSt), Methyl Methacrylate (MMA), Divinyl Benzene (DVB), sulphobetaine surfactant (dodecyl dimethyl betaine surfactant) and Ammonium Persulfate (APS) were purchased from Chengdu Kelong Chemical Reagents Corporation (PR China) and were used in the tests without further purification. DOSZ as emulsifier was supplied by the Nanjing Chemlin Chemical Industry Co., $L t d$. Hydrolysis polyacrylamide KYPAM-II was purchased from Beijing Heng Ju Co., Ltd. The Ingredients of formation brine used in the experiment are listed in Table 1. Oil with a viscosity of $10 \mathrm{mPa}$ s and a density of $0.82 \mathrm{~g} / \mathrm{cm}^{3}$ at $75^{\circ} \mathrm{C}$ was obtained from Y201 well in Yanchang Oilfield, PR China.

\subsection{Instrument}

A Fourier Transform Infrared Spectroscope (Nicolet 6700) and a Scanning Electron Microscope (SEM) ZEISS EV0 MA15, produced by Carl Zeiss Microscopy Co., Ltd, Germany, and laser particle size analyzer (LPSA) produced by Malvern Co., Ltd (UK) were used for the investigation. The Thermo Gravimetric Analyzer (TGA) was purchased from Switzerland. A multi-function core displacement device was purchased from Hai'an County Oil Scientific Instrument Co., Ltd, China. An OWC-9360 high speed stirring apparatus was obtained from Shenyang Institute of Aeronautical Engineering, PR China.

\subsection{Preparation of polymer nanospheres via emulsion polymerization}

The poly (MSt-MMA) nanospheres were prepared by emulsion polymerization. First, $20 \mathrm{wt} \% \mathrm{MSt}$ monomer and 5 wt\% MMA monomer were added in $250 \mathrm{~mL}$ three-neck flask equipped with a nitrogen inlet. 0.30\% Divinyl Benzene (DVB) crosslinking agent, $2.0 \mathrm{wt} \%$ Disodium 4-Dodecyl2,4'-Oxydiben Zenesulfonate (DOZS) emulsifier and $2.0 \mathrm{wt} \%\left(\mathrm{NH}_{4}\right)_{2} \mathrm{~S}_{2} \mathrm{O}_{8}$ initiator were added into the threeneck flask in turn. The internal temperature then was raised in a linear manner from room temperature to $75^{\circ} \mathrm{C}$ over 20 min and then kept at $75^{\circ} \mathrm{C}$ for $8 \mathrm{~h}$. The cross-linked $\mathrm{P}$ (MSt-co-MMA) nanospheres were obtained.

\subsection{Optimization of components of the three phase foam}

Anionic surfactants have the advantage of wide sourcing, good foaming performance and low cost, but their stability performance was poor. By contrast, both polymer solutions and polymer nanospheres have greater foam stability performance. The sulphobetaine surfactant (dodecyl dimethyl betaine surfactant) as foaming agent, KYPAM-II and poly(MSt-MMA) nanospheres as foam stabilizer, and formation brine were weighed according to the specified ratios using an electronic balance. They were thoroughly mixed in the beaker $(500 \mathrm{~mL})$ and the foaming solutions were obtained. The foam was prepared by stirring at a $4000 \mathrm{rpm}$ rotation rate for $60 \mathrm{~s}$ in Warning Blender. The generated foam was poured into $1000 \mathrm{~mL}$ measuring cylinder. Original foaming volume $\left(V_{\max }\right)$ was recorded. The time (half-life $t_{1 / 2}$ ) was recorded when the foam coalesced and reduced to half of foaming volume. According to FCI, the foaming performance and foam stability were determined. The better foam stability is and the bigger foaming volume is, the larger FCI value is:

$$
F C I=0.75 V_{\max } t_{1 / 2}
$$

where equation (1), FCI is defined as the foam composite index; $V_{\max }$ is the maximal of foam volume, that is, original foaming volume; $t_{1 / 2}$ is the half-life period of the foam.

\subsection{Evaluation of temperature and salt resistance}

According to the range analysis of the orthogonal test array, the experimental data showed that the primary and secondary factors influencing FCI could be obtained. The foaming ability and half-life of foam generated by the optimal parameter combination was measured at different temperatures and salinities.

\subsection{Oil displacement efficiency}

A core oil-displacement simulation test of the three phase foam was undertaken, as shown in Figure 1. The sizes of artificial cores were measured using a Vernier caliper. Then, the core was put into the thermostat and it was saturated by the formation water. The porosity and permeability of the core were calculated according to the test results. The core displacement experiment was carried out at $75{ }^{\circ} \mathrm{C}$ and the outlet pressure was atmospheric pressure.

\section{Results and discussion}

\subsection{Structure characterization}

An example infrared spectrum of poly (MSt-MMA) nanospheres was determined by FTIR, as was shown in Figure 2 . The absorption peak at $3014 \mathrm{~cm}^{-1}$ belonged to $\mathrm{C}=\mathrm{C}$ stretching vibration of the benzene ring skeleton. The absorption peaks at $1596 \mathrm{~cm}^{-1}, 1498 \mathrm{~cm}^{-1}$ and $1457 \mathrm{~cm}^{-1}$ belonged to the benzene skeleton characteristic peaks and the peaks at $762 \mathrm{~cm}^{-1}$ and $701 \mathrm{~cm}^{-1}$ belonged to the mono-substituted benzene peaks. The peak at $1735 \mathrm{~cm}^{-1}$ belonged to ester characteristic peak and the peak at $2941 \mathrm{~cm}^{-1}$ methyl vibration peak. The double bond characteristic absorption peak did not appear at $1660 \mathrm{~cm}^{-1}$, which indicates that the double bond has been opened. Thus, the crosslinking copolymer poly (MSt-MMA) nanospheres was obtained. 
Table 1. Composition of formation brine.

\begin{tabular}{cccccccr}
\hline Ion & $\mathrm{Na}^{+}$ & $\mathrm{K}^{+}$ & $\mathrm{Ca}^{2+}$ & $\mathrm{Mg}^{2+}$ & $\mathrm{Cl}^{-}$ & $\mathrm{HCO}_{3}^{-}$ & Total ion \\
\hline Concentration $\mathrm{mg} / \mathrm{L}$ & 16181 & 5326 & 4266 & 3217 & 35297 & 1254 & 65541 \\
\hline
\end{tabular}

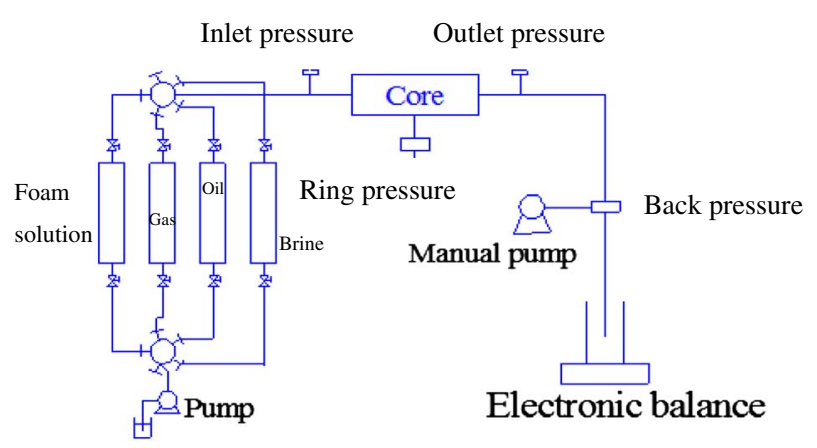

Fig. 1. A flow diagram of the core displacement apparatus.

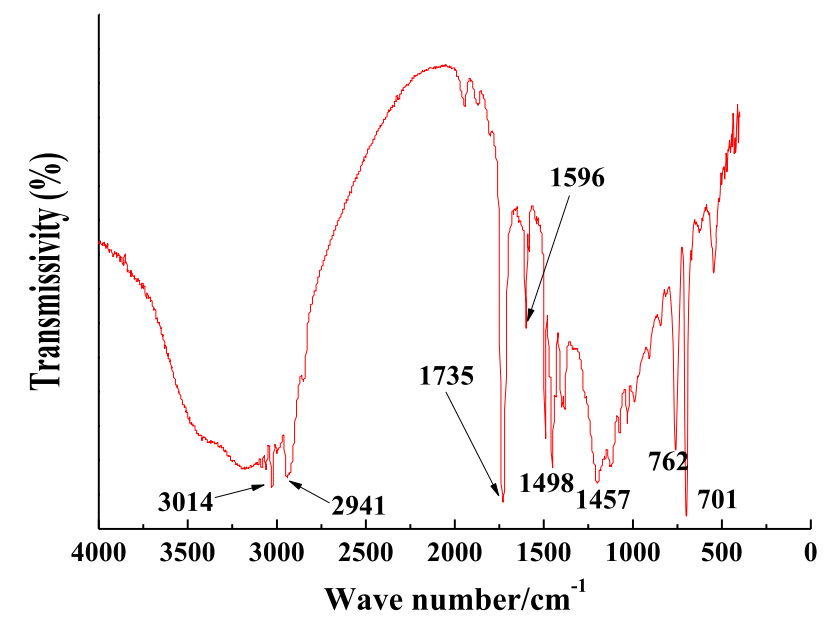

Fig. 2. Infrared spectra of the poly (MSt-MMA) nanospheres.

\subsection{LPSA analysis}

The size of poly (MSt-MMA) nanospheres was determined by LPSA, and the results were illustrated in Figure 3. The crosslinking copolymer nanospheres had outstanding mono-dispersion and the average diameter was about $80 \mathrm{~nm}$.

\subsection{SEM analysis}

The morphology and size of poly (MSt-MMA) nanospheres were characterized by SEM, as was shown in Figure 4 . The nanosphere was spherical, and the average particle diameter also was about $80 \mathrm{~nm}$ and as same as the diameter by LPSA.

\subsection{TG analysis}

The TG curve of the poly (MSt-MMA) nanospheres is shown in Figure 5. The poly (MSt-MMA) nanospheres

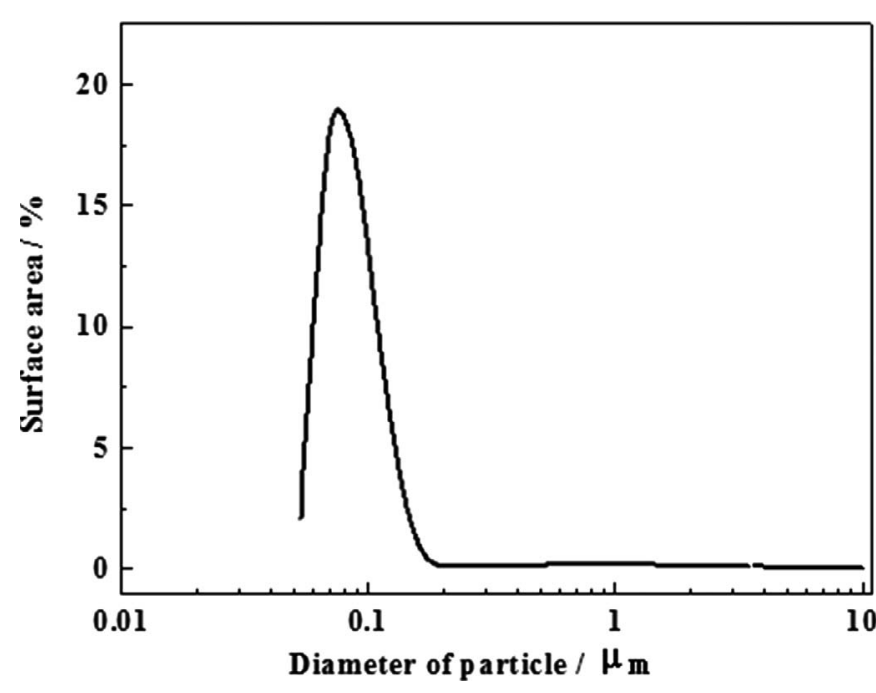

Fig. 3. Size distribution of the poly (MSt-MMA) nanospheres.

had very small weight loss of $1.2 \%$ at $183{ }^{\circ} \mathrm{C}$. The poly (MSt-MMA) nanospheres had significant weight loss of $6.4 \%$ at $375^{\circ} \mathrm{C}$. The major weight loss of the poly (MSt-MMA) nanospheres at $452{ }^{\circ} \mathrm{C}(92.4 \%)$. Therefore, the poly (MSt-MMA) nanospheres had a decomposition temperature of $375{ }^{\circ} \mathrm{C}$. The result indicated that poly (MSt-MMA) nanospheres had good thermal stability.

\subsection{Orthogonal experiment of preparing three phase foam}

The factors and levels of the orthogonal matrix tests are listed in Table 2, and the test results and analyses are summarized in Table 3. The test data revealed that the main effect factors on the performance of the foam, in turn, are the polymer, then surfactant and nanospheres. The maximum value of Foam Composite Index (FCI) was $710235 \mathrm{~mL} \mathrm{~s}$ in the nine experiments when the foam solution consisted of 0.10 wt $\%$ KYPAM-II, 0.10 wt $\%$ sulphobetaine surfactant (dodecyl dimethyl betaine surfactant) and 0.04 wt\% poly(MSt-MMA) nanospheres. The optimum formula was $0.12 \mathrm{wt} \% \mathrm{KYPAM}-\mathrm{II}, 0.10 \mathrm{wt} \%$ sulphobetaine surfactant, 0.04 wt $\%$ poly (MSt-MMA) nanospheres by orthogonal experiment and the FCI of the optimum formula was $855625 \mathrm{~mL} \mathrm{~s}$, as was used in the following tests.

\subsection{Assessment of properties}

(1) Temperature tolerance

The volume and half-life of the optimum foam formula, at different temperatures, are shown in Figure 6. With the 


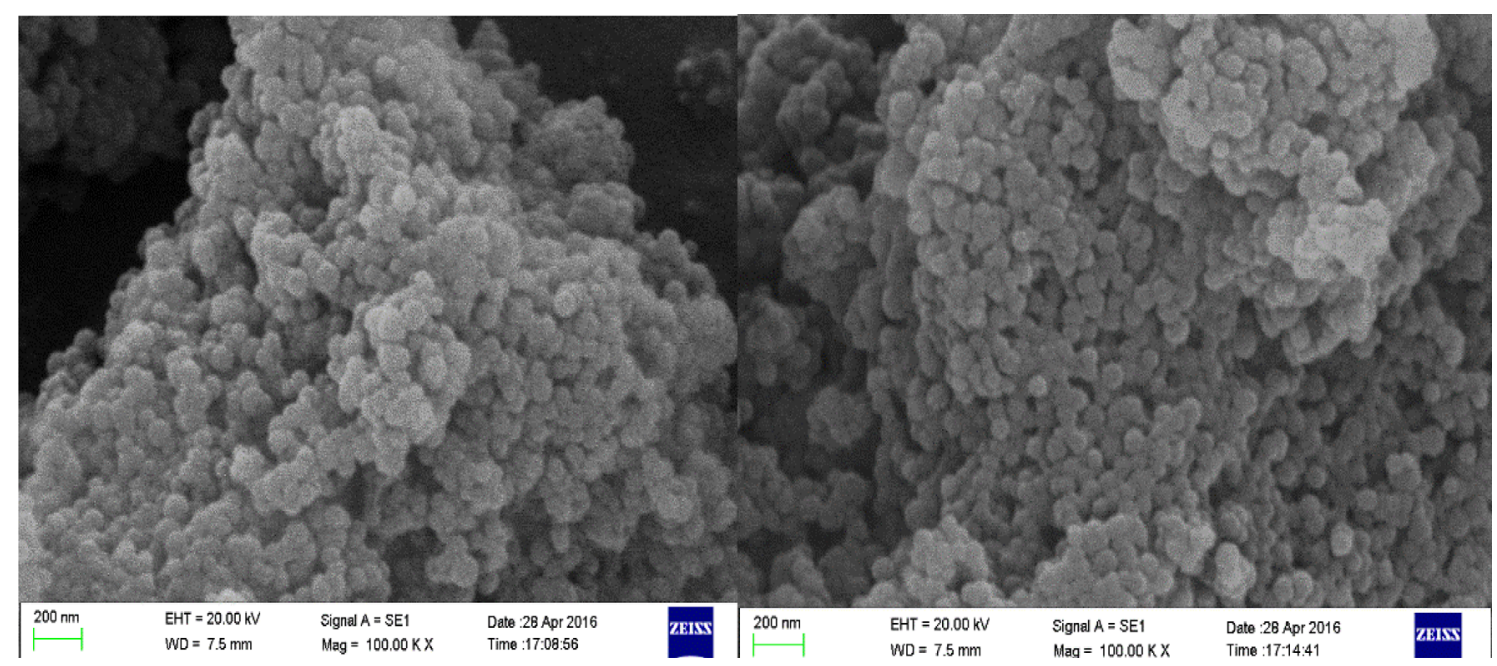

Fig. 4. SEM of poly (MSt-MMA) nanospheres.

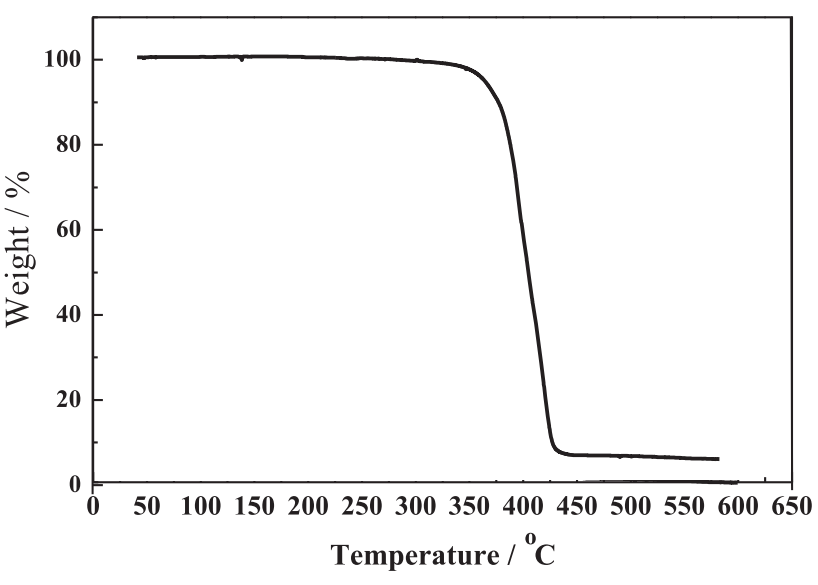

Fig. 5. TG analysis curve of poly(MSt-MMA) nanospheres.

increase of the temperature, the volume of the three phase foam reduced very little, because dodecyl dimethyl betaine surfactant had good temperature tolerance and the changes of temperature almost effect the hydrophile-lipophile balance and surface intension. But the half-life of the three phase foam always decreased significantly, because the viscosity of the system reduced obviously and the evaporation of water and gas diffusion were accelerated when the temperature increased, which led to liquid film rapid thinning. By means of the calculation using equation (1), the FCIs of the three phase foams were $484537 \mathrm{~mL} \mathrm{~s}$ at $50{ }^{\circ} \mathrm{C}$ and $175500 \mathrm{~mL}$ s at $90{ }^{\circ} \mathrm{C}$, respectively.

\section{(2) Salinity tolerance}

As was displayed in Figure 7, when the salinity $(\mathrm{NaCl})$ was in the range of $1 \times 10^{4} \sim 5 \times 10^{4} \mathrm{mg} / \mathrm{L}$, with the increase of salinity, the foam volume expanded and remained stable while the half-life declined and at last FCI remained constant. When the electrolyte was added, the diffusion double layers were compressed and the
Table 2. Factors and levels of orthogonal experiment.

\begin{tabular}{lccc}
\hline $\begin{array}{l}\text { Factor } \\
\text { level }\end{array}$ & $\begin{array}{c}\text { Nanospheres } \\
(\mathrm{wt} \%)\end{array}$ & $\begin{array}{c}\text { Sulphobetaine } \\
\text { surfactant (wt\%) }\end{array}$ & $\begin{array}{c}\text { KYPAM-II } \\
\text { (wt\%) }\end{array}$ \\
\hline 1 & 0.040 & 0.06 & 0.06 \\
2 & 0.053 & 0.08 & 0.08 \\
3 & 0.066 & 0.10 & 0.10 \\
4 & 0.079 & 0.12 & 0.12 \\
\hline
\end{tabular}

repulsive force between hydrophilic ions weakened, so the surfactant molecules arranged more closely on the surface and the foam was more stable. However, with the increase in the electrolyte concentration, the charged double layer bubble film was repulsed to avoid further weakening stable discharge and foam stability was decreased.

In summary, the KYPAM-II and the poly(MSt-MMA) nanospheres, as important factors, maintain a longer foam half-life than do foaming systems with foaming agent. The FCI of foam systems at high temperature is smaller than those at low temperature. In consequence, the foam solution can be used for high temperature reservoirs with high salinity in the injected water wells.

\section{(3) Aging stability}

Dependent on the formation permeability, injection rate and well spacing, the foam flooding system often stays in the formation to last several months or years during the displacement process. If oxygen and metals are dissolved in solution, high temperature will promote the degradation of surfactants and polymer. Therefore, its aging stability is very important to the pilot application. We investigated the aging stability for 160 days. As was showed in Figure 8, under reservoir conditions, FCI changed very little, and the system didn't appear to precipitate and floater. It illustrated that the properties of three phase foam flooding system could keep stability during the displacing period. 
Table 3. Results and analysis of orthogonal experiment.

\begin{tabular}{|c|c|c|c|c|c|c|}
\hline Test Number & $\begin{array}{c}\text { Nanospheres (A) } \\
\text { wt \% }\end{array}$ & $\begin{array}{l}\text { Surfactant B } \\
(\text { wt } \%)\end{array}$ & $\begin{array}{c}\text { Polymer C } \\
\text { (wt\%) }\end{array}$ & $\begin{array}{l}\text { Foam volume } \\
(\mathrm{mL})\end{array}$ & $\begin{array}{l}\text { Half-life } \\
\text { period }(\mathrm{s})\end{array}$ & $\begin{array}{l}\text { Foam composite } \\
\text { index }(\mathrm{mL} \mathrm{s})\end{array}$ \\
\hline $1 \#$ & 0.04 & 0.06 & 0.06 & 730 & 370 & 202575 \\
\hline $2 \#$ & 0.04 & 0.08 & 0.08 & 710 & 760 & 404700 \\
\hline $3 \#$ & 0.04 & 0.10 & 0.10 & 770 & 1230 & 710325 \\
\hline $4 \#$ & 0.04 & 0.12 & 0.12 & 780 & 924 & 540540 \\
\hline $5 \#$ & 0.053 & 0.06 & 0.06 & 710 & 628 & 334410 \\
\hline $6 \#$ & 0.053 & 0.08 & 0.08 & 770 & 390 & 225225 \\
\hline $7 \#$ & 0.053 & .0 .10 & 0.10 & 770 & 918 & 530145 \\
\hline $8 \#$ & 0.053 & 0.12 & 0.12 & 780 & 820 & 479700 \\
\hline $9 \#$ & 0.066 & 0.06 & 0.10 & 710 & 520 & 276900 \\
\hline $10 \#$ & 0.066 & 0.08 & 0.12 & 770 & 910 & 525525 \\
\hline $11 \#$ & 0.066 & 0.10 & 0.06 & 770 & 855 & 493762 \\
\hline $12 \#$ & 0.066 & 0.12 & 0.08 & 720 & 664 & 358560 \\
\hline $13 \#$ & 0.079 & 0.06 & 0.12 & 770 & 1215 & 701668 \\
\hline $14 \#$ & 0.079 & 0.08 & 0.10 & 750 & 531 & 298125 \\
\hline $15 \#$ & 0.079 & 0.10 & 0.08 & 770 & 720 & 415800 \\
\hline $16 \#$ & 0.079 & 0.12 & 0.06 & 780 & 444 & 259740 \\
\hline $\mathrm{K}_{1}$ & 1858140 & 1515553 & 1181302 & & & \\
\hline $\mathrm{K}_{2}$ & 1569480 & 1453575 & 1513470 & & & \\
\hline $\mathrm{K}_{3}$ & 1654747 & 2150032 & 1765050 & & & \\
\hline $\mathrm{K}_{4}$ & 1675333 & 1638540 & 2297878 & & & \\
\hline$\overline{\mathrm{K}}_{1}$ & 464535 & 378888 & 295326 & & & \\
\hline$\overline{\mathrm{K}}_{2}$ & 392370 & 363394 & 378368 & & & \\
\hline$\overline{\mathrm{K}}_{3}$ & 413678 & 537508 & 441262 & & & \\
\hline$\overline{\mathrm{K}}_{4}$ & 418833 & 409635 & 574469 & & & \\
\hline Range & 72165 & 174114 & 279143 & & & \\
\hline $\begin{array}{l}\text { The order of } \\
\text { factor }\end{array}$ & \multicolumn{6}{|c|}{$\mathrm{C}>\mathrm{B}>\mathrm{A}$} \\
\hline Excellent level & $\mathrm{A}_{4}$ & $\mathrm{~B}_{3}$ & $\mathrm{C}_{4}$ & & & \\
\hline $\begin{array}{l}\text { Optimum } \\
\text { combination }\end{array}$ & \multicolumn{6}{|c|}{$\mathrm{A}_{4} \mathrm{~B}_{3} \mathrm{C}_{4}$} \\
\hline
\end{tabular}

(4) Foam apparent viscosity

Pressure drop in foam coreflood was determined and foam apparent viscosity was calculated by equation (2) in literature (Heller, 1994; Ma et al., 2013) as follows:

$$
\mu=\frac{4 n}{3 n+1} \frac{\pi R^{4} \Delta \mathrm{P}}{8 Q L}
$$

where equation (2), $\mu$ - foam apparent viscosity $(\mathrm{cP})$; $n$ - power law index, in general, $n=1 ; \Delta \mathrm{P}$ - pressure difference between core inlet and outlet (Psi); $R$ - inner radius of the core (inch); $Q$ - volumetric flow rate under the experimental temperature and pressure $\left(\mathrm{cm}^{3} / \mathrm{min}\right)$; $L$ - length of the core (foot).

Basic parameters of the core in the experiment were length 0.2664 foot, diameter 0.9855 inch $(d=2 \mathrm{R})$, weight $96.68 \mathrm{~g}$, core permeability $8.67 \times 10^{-3} \mu \mathrm{m}^{2}$ and porosity $9.22 \%$. Flow rate was $0.8 \mathrm{~cm}^{3} / \mathrm{min}$ and gas liquid ratio was 3:1. The pressure drop in the system was recorded every $30 \mathrm{~s}$. Pressure drop 2540.5 Psi was obtained in steady-state during the displacement.

A typical foam apparent viscosity history is described in the injection experiment, as is shown in Figure 9. The foam apparent viscosity reached a steady state after about 1.1 Total Pore Volumes (TPV). A lot of white tiny uniformed foam flowed out the core outlet, which proved that foam was created in the coreflood experiments. The sudden pressure changes at 1.1 and $3.2 \mathrm{TPV}$ were due to the operation of refilling injectants. The steady-state foam apparent viscosity (about $205 \mathrm{cp}$ ) for 3:1 gas liquid ratio was obtained by averaging the plateau viscosities.

Pressure difference and apparent viscosity quickly increased with the increase of injected total pore volume and the value of pressure difference, and apparent viscosity of three phase foam flooding were more than that of water flooding when injected total pore volume was same, which 


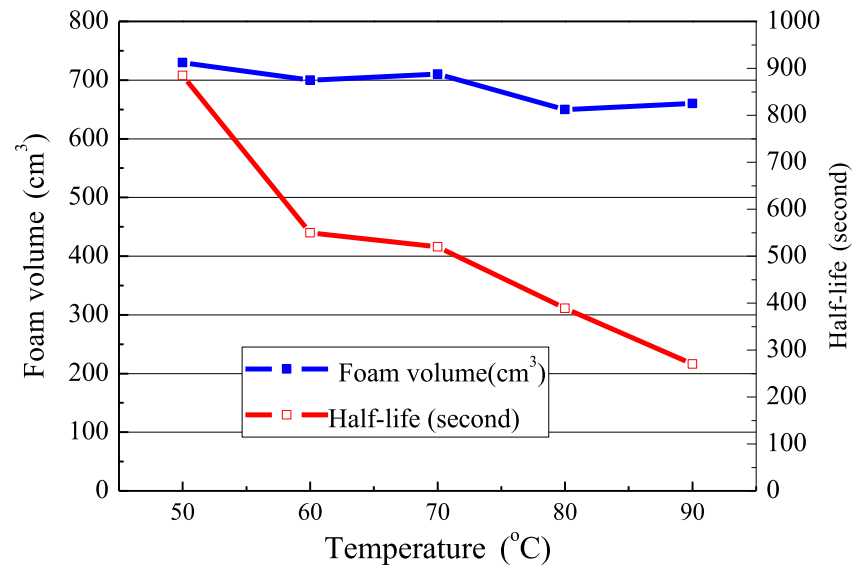

Fig. 6. Temperature tolerance test of the optimum formula (0.12 wt\% KYPAM-II, 0.10 wt\% sulphobetaine surfactant, $0.04 \mathrm{wt} \%$ poly(MSt-MMA) nanospheres, $\left.\mathrm{C}_{\mathrm{NaCl}}=8 \times 10^{4} \mathrm{mg} / \mathrm{L}\right)$.

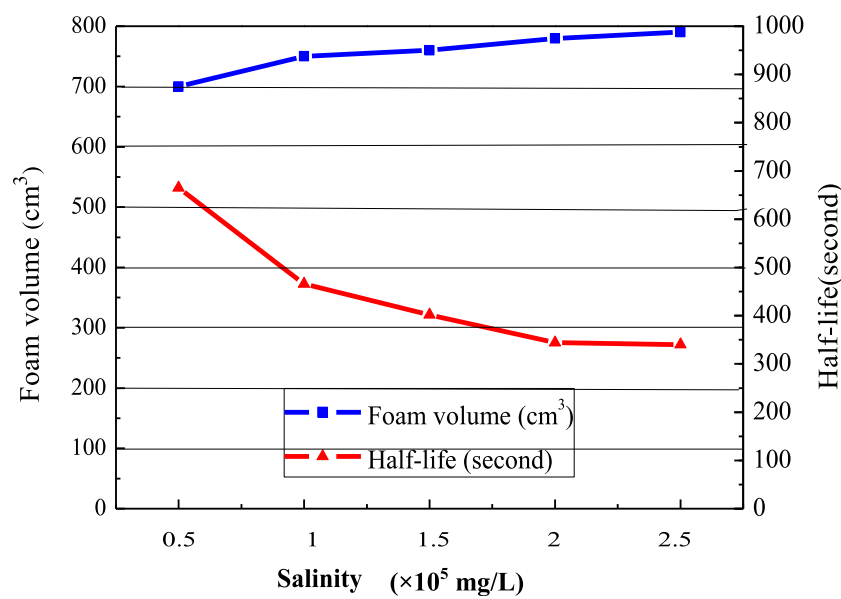

Fig. 7. Salinity tolerance test of the optimum formula (0.12 wt\% KYPAM-II, 0.10 wt\% sulphobetaine surfactant, 0.04 wt\% poly(MSt-MMA) nanospheres, $45^{\circ} \mathrm{C}$ ).

suggested that foam was constantly created in the coreflood experiments.

As was seen from Figure 9, with the increase of injected total pore volume, the resistance gradually increased, and the apparent viscosity of the foam increased sharply, which indicated that the amounts of the three phase foam increased gradually. Foam in the porous media continued to produce and increase. When the injection total pore volume reached 1.1 PV, the produced bubble amounts and burst bubble amounts reached a dynamic balance, so that the resistance increased to the maximum. When the injected total pore volume was greater than $1.1 \mathrm{PV}$, the apparent viscosity of the foam almost kept constant and the average apparent viscosity was close to $205 \mathrm{mpa}$ s, that was, the foam reached a stable dynamic state.

(5) Resistance coefficient and residual resistance coefficient

Resistance coefficient $\left(F_{\mathrm{r}}\right)$ is a technical index to evaluate the foam system improving mobility ratio. The resistance

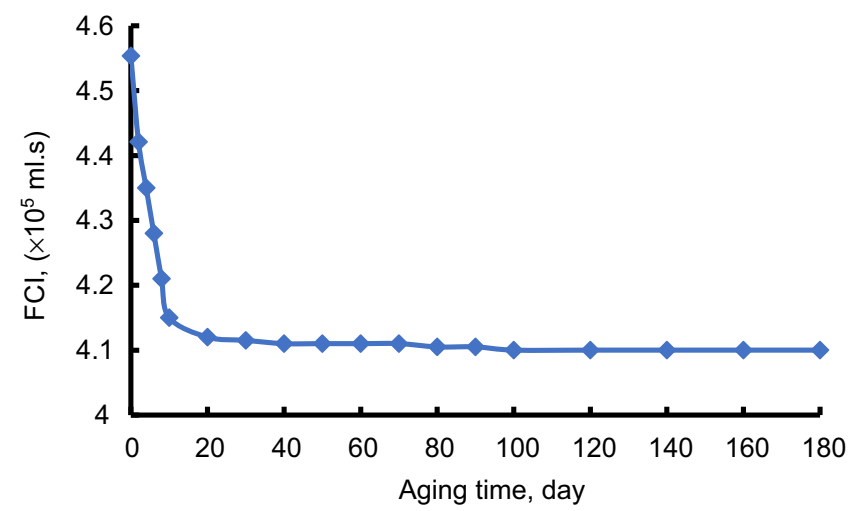

Fig. 8. FCI versus aging time $(0.12 \mathrm{wt} \%$ KYPAM-II, $0.10 \mathrm{wt} \%$ sulphobetaine surfactant, 0.04 wt $\%$ poly(MSt-MMA) nanospheres, formation brine, $75^{\circ} \mathrm{C}$ ).

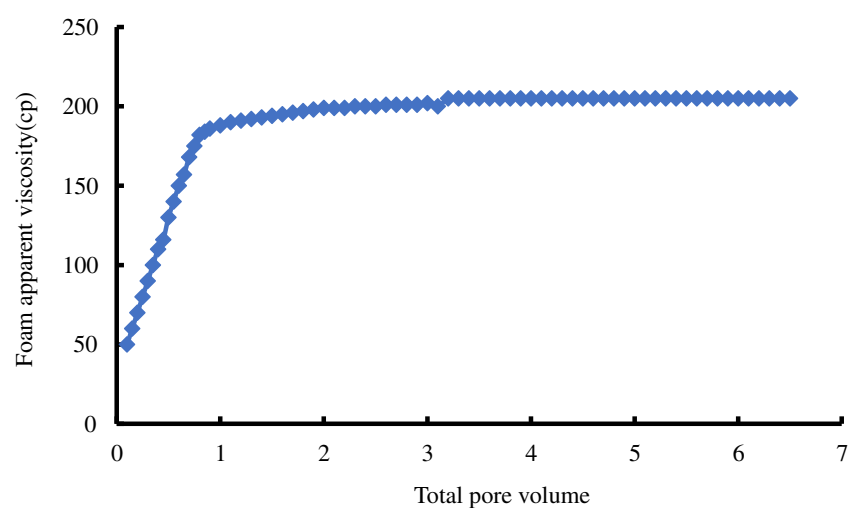

Fig. 9. Typical foam apparent viscosity history of injection versus total pore volume. (Flow rate $0.8 \mathrm{cc} / \mathrm{min}$, gas liquid ratio $3: 1$, formation brine, $75^{\circ} \mathrm{C}$.)

coefficient is defined as the ratio of the differential pressure of profile control agent flow through the core to that of water flow through the same core at same flow rate. Equation (3) is as follows:

$$
F_{r}=\triangle P_{\mathrm{G}} / \triangle P_{w}
$$

where equation (3), $\triangle P_{\mathrm{G}}$ is velocity displacement pressure of profile control agent; $\triangle P_{\mathrm{w}}$ is velocity differential pressure of certain brine.

It is called the residual resistance coefficient $\left(F_{\mathrm{rr}}\right)$ to reflect the ability of the foam flooding to reduce the permeability of porous media. Its value is equal to the ratio of the permeability of brine phase after the foam flooding is injected into the core to the permeability of brine phase before the foam is injected into the core. Equation (4) is as follows:

$$
F_{\text {rr }}=K_{\mathrm{P}} / K_{\mathrm{b}}
$$

where equation (4), $K_{\mathrm{P}}$ is the permeability of brine phase after injected the foam; $\triangle K_{\mathrm{b}}$ is the permeability of brine phase before injected the foam. 
Table 4. Resistance coefficient and residual resistance coefficient.

\begin{tabular}{lcccc}
\hline $\begin{array}{l}\text { Sand- } \\
\text { packed } \\
\text { tube }\end{array}$ & $\begin{array}{c}\text { Porosity Permeability } \\
\%\end{array}$ & $\begin{array}{c}\text { Resistance } \\
\times 10^{-3} \mu \mathrm{m}^{2}\end{array}$ & $\begin{array}{c}\text { Residual } \\
\text { coefficient }\end{array}$ & $\begin{array}{c}\text { resistance } \\
\text { coefficient }\end{array}$ \\
\hline $1 \#$ & 13.3 & 10.3 & 82.9 & 4.2 \\
$2 \#$ & 9.1 & 1.52 & 128.5 & 5.5 \\
\hline
\end{tabular}

Table 5. Physical properties of the sandstone cores.

\begin{tabular}{|c|c|c|c|c|c|}
\hline $\begin{array}{l}\text { Core } \\
\text { number }\end{array}$ & $\begin{array}{c}\text { Diameter } \\
(\mathrm{cm})\end{array}$ & $\begin{array}{l}\text { Length } \\
\text { (cm) }\end{array}$ & $\begin{array}{l}\text { Porosity } \\
(\%)\end{array}$ & $\begin{array}{c}\text { Permeability } \\
\left(\times 10^{-3} \mu \mathrm{m}^{2}\right)\end{array}$ & $\begin{array}{c}\text { Oil } \\
\text { saturation } \\
(\%)\end{array}$ \\
\hline $3 \#$ & 2.43 & 5.17 & 12.79 & 10.62 & 89.3 \\
\hline $4 \#$ & 2.53 & 5.59 & 8.16 & 2.19 & 88.7 \\
\hline
\end{tabular}

After brine was saturated by flow rate $0.1 \mathrm{~mL} / \mathrm{min}$, $200 \mathrm{mg} / \mathrm{L}$, foam was injected $3 \mathrm{PV}$ into the two sandpacked. Then $50 \mathrm{PV}$ brine was injected. Initial brine flooding pressure, the pressure after injecting $3 \mathrm{PV}$ foam and the pressure after injecting $50 \mathrm{PV}$ brine flooding were noted, respectively. The results of resistance coefficient and residual resistance coefficient of the three phase foam were calculated and were shown in Table 4.

Resistance coefficient of low permeability core was more than that of high permeability core, but both of residual resistance coefficients were small and similar. The experiment results indicated that the three phase foam had good profile control ability, and was low damage to the low permeability layer.

(6) Displacement oil efficiency

Physical properties of the sandstone cores and flooding efficiency of single core by using three phase foam are shown in Tables 5 and 6 , respectively. Foam flooding recovers additionally $13.5 \mathrm{wt} \%$ and $18.6 \mathrm{wt} \%$ oil in high permeability core and low permeability core, respectively, when the difference of permeability is approximately 5 . The difference of permeability $\left(K_{\mathrm{mn}}\right)$ is the ratio of the maximum permeability $\left(K_{\max }\right)$ to the minimum permeability $\left(K_{\min }\right)$, showing the distribution and difference in degree of permeability. The average displacement efficiency of three phase foam is $16.1 \mathrm{wt} \%$.

\section{(7) Profile control}

Physical properties of the sandstone cores and flooding efficiency of double core by using three phase foam are shown in Tables 7 and 8 , respectively. The double parallel core displacement experiments were performed. The experiments were carried out at approximately $75{ }^{\circ} \mathrm{C}$ and the flow rate $0.2 \mathrm{~mL} / \mathrm{min}$ during saturating brine, saturating oil, water flooding for each core, respectively. Then the double cores were paralleled with the same entrance and the same exit. The foam were injected from entrance, and flowed through two cores. Finally, the foam flowed out from
Table 6. Summary flooding tests in core displacement device.

\begin{tabular}{lcccc}
\hline Foam \\
$\begin{array}{l}\text { Core } \\
\text { number }\end{array}$ & $\begin{array}{c}\text { Water } \\
\text { flooding } \\
\text { recovery } \\
\text { (wt\%) }\end{array}$ & $\begin{array}{c}\text { Three phase foam } \\
\text { flooding efficiency } \\
\text { (wt\%) }\end{array}$ & $\begin{array}{c}\text { EOR } \\
\text { (wt\%) }\end{array}$ \\
\hline $3 \#$ & 0.5 & 47.7 & 13.5 & 16.1 \\
$4 \#$ & 0.5 & 49.3 & 18.6 & \\
\hline
\end{tabular}

Table 7. Physical properties of the sandstone cores.

Oil

Core Diameter Length Porosity Permeability saturation

\begin{tabular}{lccccc} 
number & $(\mathrm{cm})$ & $(\mathrm{cm})$ & $(\%)$ & $\left(\times 10^{-3}{\left.\mu \mathrm{m}^{2}\right)}^{2}\right.$ & $(\%)$ \\
\hline $5 \#$ & 2.36 & 5.75 & 12.53 & 9.43 & 90.6 \\
$6 \#$ & 2.34 & 5.56 & 8.98 & 1.89 & 87.9 \\
\hline
\end{tabular}

Table 8. Summary flooding tests in core displacement device.

\begin{tabular}{lcccc}
\hline Foam \\
$\begin{array}{l}\text { Core } \\
\text { number }\end{array}$ & $\begin{array}{c}\text { Water } \\
\text { flooding } \\
\text { recovery } \\
\text { (wt\%) }\end{array}$ & $\begin{array}{c}\text { Three phase foam } \\
\text { flooding efficiency } \\
\text { (wt\%) }\end{array}$ & $\begin{array}{c}\text { EOR } \\
\text { (wt\%) }\end{array}$ \\
\hline $5 \#$ & 0.5 & 53.1 & 18.2 & 21.7 \\
$6 \#$ & 0.5 & 46.5 & 27.3 & \\
\hline
\end{tabular}

exit. Yanchang crude oil with viscosity of $8.3 \mathrm{mPa}$ s at $75^{\circ} \mathrm{C}$ and formation brine were used in the experiment. Throughout the experiment, the cores were first saturated with Yanchang crude oil and formation brine was injected until the water-cut was $98 \%$; then $0.5 \mathrm{PV}$ three phase foam was injected; finally, then only $10 \mathrm{PV}$ formation brine was injected.

The difference between the permeability of the high and low permeable layers is about five times in turn, too. Three phase foam flooding efficiencies were $18.2 \mathrm{wt} \%$ and $27.3 \mathrm{wt} \%$ in high permeability core and low permeability core, respectively. Average EOR was $21.7 \mathrm{wt} \%$, which is more than that of two phase foam $(15.9 \mathrm{wt} \%)$ in the literature [19]. More subsequent fluid flowed into the low permeable layers after the foam was injected. The experiment results showed the three phase foam have good profile control.

\section{Results of pilot test}

From May 2015 to September 2015, a pilot test of three phase foam flooding was performed in the Y201 well group and the Y204 well group. The pilot test achieved initial success. The field injection foam pressure was between 
14.5 and 17.5 MPa. In Y201 well, normal injection pressure was about $15.7 \mathrm{MPa}$, and in Y204 well, normal injection pressure was about $17.1 \mathrm{MPa}$, injection pressures of the two wells were lower than the scheme of limits $19.5 \mathrm{MPa}$. Two well groups were beginning to bear fruit from June 2015 , and production liquid amount increased slightly, then water-cut decreased greatly and oil production increased a lot. From June 1 to September 25, cumulative injected foam liquid was $1252.5 \mathrm{~m}^{3}$, the cumulative gas injection $142550.7 \mathrm{~m}^{3}$, conversion of underground foam volume $4415.6 \mathrm{~m}^{3}$, a total of increased oil of corresponding two well groups was $567.9 t$. We estimated preliminarily that the ratio of input and output of the two well groups was $1: 2.72$, which showed that recovery oil of the three phase foam flooding was considerable.

\section{Conclusion}

The crosslinked polymer nanospheres as a foam stabilizing agent were prepared by emulsion polymerization with MSt and MMA as monomers, DVB as crosslinker, OP-10 as emulsifier and APS as initiator. The poly(MSt-MMA) nanospheres were characterized by FT-IR, LPSA, SEM and TGA. The average particle of the crosslinked polymer nanospheres was $80 \mathrm{~nm}$. The optimum formulation of the three phase foam was screened by the orthogonal experiment. The temperature and salt tolerance of three phase foam were very good. Flooding oil experiment showed that the average displacement efficiency of three phase foam system was $16.1 \mathrm{wt} \%$ in single core experiments and $21.7 \mathrm{wt} \%$ in double core experiments. Resistance coefficient of low permeability core was more than that of high permeability core, but their residual resistance coefficients were small and similar, which indicated that the three phase foam had good profile control ability and generated low damage to the low permeability layer for extra-low permeability reservoirs. Thus, three phase foam flooding has great prospects for EOR in extra-low permeability reservoirs.

Acknowledgments. The work was supported by key project of opening experiments of Southwest Petroleum University-2017 (No.x151514kcl16).

\section{References}

1 Wang H., Liao X.W., Zhao X. (2014) The influence of $\mathrm{CO}_{2}$ solubility in reservoir water on $\mathrm{CO}_{2}$ flooding and storage of $\mathrm{CO}_{2}$ injection into a water flooded low permeability reservoir, Energ Source Part A: Recovery Utilization Environ. Effects 36, 8, 815-821.

2 Chang H.L., Zhang Z.Q., Wang Q.M., Xu Z.S., Guo Z.D., Sun H.Q. (2006) Advances in polymer flooding and alkaline/surfactant/polymer processes as developed and applied in the People's Republic of China, J. Pet. Technol. $\mathbf{1 2}, 58,84-89$.
3 Zhu Y., Hou Q., Jian G., Desheng M.A., Zhe W. (2013) Current development and application of chemical combination flooding technique, Petrol. Explor. Dev. 40, 1, 96-103.

4 Mandal A. (2015) Chemical flood enhanced oil recovery: a review, Int. J. Oil Gas Coal. Tech. 9, 3, 241-252.

$5 \mathrm{Yu}$ Q., Jiang H., Song Y., Yi Z., Zhang C. (2012) Chemical flooding for enhanced recovery, Energ Source Part A: Recovery Utilization Environ. Effects 34, 5, 478-483.

6 Zhou M., Wang C., Xing T., Li S., Zhang Z., Luo G. (2015) Studies on foam flooding for saline reservoirs after polymer flooding, J. Petrol. Sci. Eng. 135, 410-420.

7 Wang J., Dong M. (2009) Optimum effective viscosity of polymer solution for improving heavy oil recovery, J. Petrol. Sci. Eng. 67, 3, 155-158.

8 Sharma T., Velmurugan N., Patel P., Chon B.H., Sangwai J.S. (2015) Use of oil-in-water pickering emulsion stabilized by nanoparticles in combination with polymer flood for enhanced oil recovery, Pet. sci. technol. 33, 17-18, 1595-1604.

9 Wever D.A.Z., Picchioni F., Broekhuis A.A. (2013) Comblike polyacrylamides as flooding agent in enhanced oil recovery, Ind. Eng. Chem. Res. 52, 46, 16352-16363.

10 Sun L., Wang B., Pu W., Yang H., Shi M. (2015) The Effect of foam stability on foam flooding recovery, Pet. Sci. Technol. 33, 1, 15-22.

11 Wu W.X., Tang J.B., Zhang Z.X. (2013) Selection of oil displacement agent and performance evaluation for foam complex system, Appl. Mech. Mater. 437, 1097-1100.

12 Li Z.M., Liu Z.P. (2011) Experiment study on a novel foam system for enhanced oil recovery, Adv. Mater. Res. 311-313, 396-405.

13 Sun Q., Li Z., Wang J., Li S., Jiang L., Zhang C. (2015) Properties of multi-phase foam and its flow behavior in porous media, $R S C$ Adv. 5, 83, 67676-67689.

14 Cheraghian G. (2015) An experimental study of surfactant polymer for enhanced heavy oil recovery using a glass micromodel by adding nanoclay, Pet. Sci. Technol. 33, 13-14, 1410-1417.

15 Hua Z., Lin M., Guo J., Xu F., Li Z., Li M. (2013) Study on plugging performance of cross-linked polymer microspheres with reservoirs pores, J. Petrol. Sci. Eng. 105, 3, $70-75$.

16 Zhou M., Zhao J.Z., Pu W.F., Wang X., Yang Y. (2012) Synthesis and characterization of salt resistance hydrogel microspheres by inverse suspension polymerization, E-Polymers No. 084, 1-8.

17 Zhou M., Nie X.C., Zhou L., Hou L.T., Zhao J.Z., Wang X., Yang Y. (2017) Study of crosslinked copolymer nanospheres with temperature resistance, salinity resistance, and deep profile control, J. Appl. Polym. Sci. 134, 5, 45131-45138.

18 Lin M., Zhang G., Hua Z., Zhao Q., Sun F. (2015) Conformation and plugging properties of cross-linked polymer microspheres for profile control, Colloids Surf. A Physicochem. Eng. Aspects 477, 49-54.

19 Zhou M., Wang C.W., Xing T.T., Li S.S., Zhang Z., Luo G. (2015) Studies on foam flooding for saline reservoirs after polymer flooding, J. Petrol. Sci. Eng. 135, 6, 410-420. 